\title{
Analysis of Cyanide Concentration in Five Selected Bamboo Shoots Consumed in North East India
}

\section{Sarma MP*}

Associate professor, Department of Biotechnology and HOD, Faculty of Sciences, Assam down town University, Guwahati, Assam, India

*Corresponding author: Manash Pratim Sarma, Associate professor, Department of

\section{Short Communication}

Volume 2 Issue 2

Received Date: April 02, 2018

Published Date: May 23, 2018 Biotechnology and HOD, Faculty of Sciences, Assam down town University, Guwahati, Assam, India, Email: manash3268@gmail.com

\begin{abstract}
Use of bamboo shoot by North East Indian people is very common. However, few reports have been published reporting the cyanide presence above consumable limit. Based on this the current study was designed to estimate the presence of HCN by picric acid method in selected verities of bamboo shoot consumed in NE India. The results clearly show that highest concentration of cyanide was recorded in Bambusa tulda and the least in Dendrocalamus giganteus. The study findings will be helpful in commenting upon the cyanide related food poisoning in this part of the country.

Keywords: HCN; Bamboo shoots; North East India; Picric acid test
\end{abstract}

\section{Introduction}

The bamboo that belongs to the family poaceae and is spread over 1250 species and 75 genera across the globe. India has been the home for 136 of this species of 23 genera and is one of the leading producers along with China, Burma, Philippines, Thailand, Malaysia, Indonesia and Sri Lanka. Bamboo shoots are the young edible parts of the plant and are consumed in raw, crushed, dried, fermented boiled and in the form of pickle. Bamboo shoots are a preferred edible item across the North eastern states of India which is the case for countries like US, New Zealand, China, Korea and Burma.

Not all bamboo shoots are edible. Some of the commonly consumed bamboo shoots of NE India out of the total 7 edible species are balcooa robxb, dandrocallamus giganticus and melocanna baciffera. They are preferred as are low in fats and cholesterol, high in potassium and carbohydrates and are rich in dietary fibre. Anti oxidants like phenols, steroids and flavonoids makes them beneficial food item besides being rich in vitamins, minerals (10 types) and amino acids (17 types). Beside its nutritional aspect, they are believed to have anti ageing properties, decrease blood cholesterol, acts as appetisers, enhanced appetite and are believed to have anti microbial properties.

The only major issue with bamboo shoot arises if they are not harvested as soon as they come out of ground as they develop an acidic flavour. It contains a toxic cyanoglycoside, called taxiphyllin which is activated by 
hydrolytic beta- galactosidase. Once bamboo shoots are disrupted from the plant, the taxiphyllin further breaks down in to cyanohydrins and sugars which in due course decompose to hydrocyanic acid and aldehydes and ketones [1-3]. Bamboo shoot contains $0.3-0.8 \%$ hydrogen cyanide of which $0.16 \%$ is concentrated in the tips and only $0.01 \%$ at the base. However, this problem of $\mathrm{HCN}$ may be get rid off by cooking or boiling for 2 hours. Bamboo shoots may contain as much as $1000 \mathrm{mg} / \mathrm{kg}$ hydrogen cyanide, significantly higher than the amounts detected in cassava tubers (technical report series no. 28).

The acute lethal dose of HCN in human beings has been estimated as $0.5-3.5 \mathrm{mg} / \mathrm{kg}$ body weight while in animals it is believed to be 0.66 to $15 \mathrm{mg} / \mathrm{kg}$ body weight (Reddy, 2006). Cyanide is extremely toxic to a wide spectrum of organism because of its ability of linking with metals such as $\mathrm{Fe}++, \mathrm{Mn++}$ and $\mathrm{Cu}++$ which are functional groups affecting many enzymes inhibiting the action of carbonic anhydrase and cytochrome oxidase. It ultimately blocks the oxidative phosphorylation apart from reducing the oxygen carrying capacity of the blood by combining with the iron atom [4,5]. Cyanogenic compounds that decomposes quickly when placed in boiling water. Bamboo becomes edible because of this instability [6]. Bamboo shoots may contain high levels of HCN; however, the HCN content is reduced substantially during fermentation process prior to consumption.

\section{Aim and Methodology}

With this background knowledge, the study was designed to check the concentration of HCN in five widely consumed species of bamboo shoots across North Eastern Region.

HCN concentration was calculated based previously described protocol using alkaline picrate solution. The test protocol was slightly modified than the previous one and is purely a biochemical test. The OD values were translated in to the concentration levels of $\mathrm{HCN}$ in respective samples using a mathematical calculation [7].

\section{Results and Discussion}

\begin{tabular}{|c|c|c|c|c|}
\hline Serial Number & Bamboo species & Location & OD at 625 nm & Actual Concentration of HCN (mg/g) \\
\hline 1 & Bambusa tulda & Assam & 0.14 & 1.4 \\
\hline 2 & Bambusa Pallida & Nagaland & 0.021 & 0.21 \\
\hline 3 & Bambusa auriculata & B.T.C, Assam & 0.015 & 0.15 \\
\hline 4 & Dendrocalamus giganteus & Meghalaya & 0.007 & 0.07 \\
\hline 5 & Dendrocalamus hamiltonii & Arunachal Pradesh & 0.014 & 0.14 \\
\hline
\end{tabular}

Table 1: HCN levels in five studied samples of bamboo shoots of North East India.

The results clearly show that highest concentration of cyanide was recorded in Bambusa tulda and the least in Dendrocalamus giganteus (Table 1). The total cyanide levels are highest at the tip and lowest at the base which was in accordance to a previous study by Kananbala et al., 2010 [8]. The average range of the HCN detected in the current study were also in the similar line to this study. HCN according to a WHO report are highly volatile [9], the loss of HCN at the time of fermentation is attributed to processes like slicing, peeling, cutting, repeated washing many times with water. Because of the instable nature of the Cyanogenic compounds it decomposes quickly when palced in hot water and thus most of the time is available as harmless food product [6].

In conclusion, it may be said that HCN concentration varies from species to species of bamboo shoot and the highest concentration is found in base followed by the tip portion. Also, the level decreases to acceptable limit due to fermentation processes and boiling. However the role of micro organism in this context is yet to be studied.

\section{References}

1. Conn EE (1979) Cyanogenic glycosides. International review of biochemistry. In: Biochemistry and Nutrition 1A. (Eds. Neuberger A \& Jukes TH). University Park Press, Baltimore. pp: 21-43.

2. Nartey F (1980) Toxicological aspects of cyanogenesis in tropical foodstuffs. In: Toxicology in the Tropics. (Eds Smith RL and Bababumni EA), Taylor \& Francis Ltd, London, pp: 53-73.

3. Rosling H (1994) Measuring effects in humans of dietary cyanide exposure from cassava. Acta Hort 375: 271-283. 


\section{Bioequivalence \& Bioavailability International Journal}

4. Harborne JB (1972) Cyanogenic glucosides and their function. In: Phytochemical ecology. Academic Press, London, pp.104-123.

5. Harborne JB (1993) Plant toxins and their effects on animals. In: Introduction to Ecological iochemistry. Academic Press, London, pp: 71-103.

6. Nahrstedt AF (1993) Cyanogenesis and food plants. In: Proceedings of the International Symposium on phytochemistry and agriculture, 22-24 April 1992, Van Beek TA, Breteler H, (Eds.), Wage ningen. Oxford University Press, pp: 107-129.
7. Bradbury MG, Egan SV, Bradbury JH (1999) Determination of all forms of cyanogens in cassava roots and cassava products using picrate paper kits. J Sci Food Agric 79(4): 593-601.

8. Kananbala S, Hoikhokim (2010) Cyanogen content in bamboo plants. Asian Journal of Bio Science 5(2): 178-180.

9. Cyanogenic Glycosides In Cassava And Bamboo Shoots: (2004) A Human Health Risk Assessment Technical Report Series No. 28; Food standards Australia New Zealand. 